\title{
The Metabolic Fate of Plasma Lipoproteins in Normal Subjects and in Patients with Insulin Resistance and Endogenous Hypertriglyceridaemia
}

\author{
A. H. Kissebah, S. Alfarsi, P. W. Adams and V. Wynn \\ The Alexander Simpson Laboratory for Metabolic Research, St. Mary's Hospital Medical School, London, England
}

Summary. Using $\mathrm{I}^{131}$ VLDL selectively labelled in the B-apoprotein and $\mathrm{I}^{125}$ LDL injected simultaneously into the patient we have derived some quantitative measures of VLDL and LDL metabolism in man. The effects of insulin resistance, associated with idiopathic hypertriglyceridaemia, adult onset diabetes and diabetic lipodystrophy on the metabolic behaviour of these molecules were also assessed. In the normal subjects $72-83 \%$ of the total daily plasma VLDL B-apoprotein flux was metabolised via a pathway which involved its ultimate conversion to plasma LDL, while $21-28 \%$ was degraded without such conversion. The amount of $\mathrm{B}$-apoprotein metabolised by either of these routes was proportionate to the flux rate and the two pathways accounted for the total VLDL B-apoprotein removed from the plasma. In patients with idiopathic hypertriglyceridaemia and in the adult onset diabetics the total plasma VLDL $\mathrm{B}$-apoprotein flux was higher than normal, indicating increased production of this apoprotein. On the other hand, the flux rate of plasma VLDL B-apoprotein in the patients with diabetic lipodystrophy was normal, suggesting that the increase in the circulating mass of these molecules was due to impaired clearance. In all the patients, however, the fractions of the total flux either converted to LDL or degraded were lower than normal, suggesting that insulin resistance limited the removal of this apoprotein by these pathways. The results also indicate that a fraction of the total VLDL removed from the plasma has been retained in an extravascular compartment, possibly representing VLDL molecules trapped in the vascular structures. In the control and the insulin resistant subjects the quantity of LDL apoprotein catabolised per day agreed closely with the amount derived from VLDL B-apoprotein conversion, suggesting that VLDL B-apoprotein serves as the main source of LDL apoprotein. In patients with idiopathic hypertri- glyceridaemia and in adult onset diabetics the absolute turnover rate of plasma LDL apoprotein was higher than normal, while in the lipodystrophic patients it was reduced. It is suggested that the increase in LDL turnover seen in the former groups could be an additive factor in the deposition of lipid rich material in arterial walls.

Key words: Insulin resistance, idiopathic hypertriglyceridaemia, adult onset diabetes, diabetic lipodystrophy, very low density lipoproteins (VLDL), low density lipoproteins (LDL).

In recent years several epidemiological surveys have identified a number of metabolic abnormalities associated with the development of atherosclerosis. Though the relative importance of each of these factors remains uncertain, several studies have emphasised the role of hyperinsulinaemia, with or without glucose intolerance, as an important factor in the pathogenesis of this disease $[1,2,3,4]$.

The mechanism whereby hyperinsulinaemia could initiate the atherosclerotic process is as yet unclear. The current view suggests that these patients have resistance to insulin and that the compensatory hyperinsulinaemia and/or the associated enhancement of lipolysis favour an increase in hepatic production of plasma very low density lipoproteins $[5,6]$. The latter could predispose to the deposition of lipid rich material in arterial walls. Recent studies in rats [7], guinea pigs [8] and subhuman primates [9] have indicated that the smooth muscle cell, present in the intima and media of large arteries, accumulates plasma VLDL and that the uptake of these molecules could be increased by raising their concentration. Since the 
smooth muscle is the cell that proliferates to become the lipid filled foam cell characteristic of the early lesion in atheroma, the exposure of this cell to raised levels of VLDL could be a factor in the development of this process.

Recently evidence in man $[10,11]$ has suggested that the catabolism of plasma VLDL involves in part its conversion to LDL molecules and that most, if not all, of the circulating LDL is derived from this source. It is not certain, however, whether insulin resistance could modulate the metabolic fate of plasma VLDL and its conversion to the more sinister low density lipoprotein species. This effect could be of extreme importance, since cholesterol, which is transported mainly in plasma LDL, forms the major lipid component of atheroma [12]. Furthermore, studies in human aortic smooth muscle cultures have shown that in man the avidity of these cells to bind and take up plasma $\mathrm{LDL}$ is much greater than any of the other lipoprotein species [13].

The aim of this study was to quantitate the metabolic fate of plasma VLDL in man, its conversion to LDL and the catabolism of the latter. The effects of insulin resistance on these processes were explored in 4 patients with idiopathic hypertriglyceridaemia, 3 adult onset diabetics and 2 subjects with diabetic lipodystrophy.

\section{Subjects}

This study was undertaken in 8 normal volunteers with serum triglyceride concentrations less than 160 $\mathrm{mg} / 100 \mathrm{ml}$. All had normal glucose tolerance (fasting plasma glucose $<100 \mathrm{mg} / 100 \mathrm{ml}, 60 \mathrm{~min}$ and $120 \mathrm{~min}$ values $<180$ and $120 \mathrm{mg} / 100 \mathrm{ml}$ respectively). Their mean age was 43 years (range 35-66) and mean body weight $69 \mathrm{~kg}$ (range 53-91), which was less than $130 \%$ of their ideal weight (determined from Documenta Geigy).

The insulin resistant group comprised 4 patients with idiopathic hypertriglyceridaemia and normal glucose tolerance, 3 untreated adult onset diabetics and 2 siblings with diabetic lipodystrophy. 3 of the patients with idiopathic hypertriglyceridaemia presented with eruptive xanthomatosis and the fourth was detected on routine biochemical screening. The diabetic subjects, apart from glycosuria detected on routine screening, were asymptomatic non-ketotic patients, who had abnormal glucose tolerance associated with hyperinsulinaemia. The lipodystrophic subjects were two male siblings in whom loss of subcutaneous fat was evident from photographs taken during adolescence. They had no clinical evidence of hepatomegaly and laboratory investigation showed no abnormality in liver or renal function.
All the patients in the insulin resistant group were males, with a mean age of 44 years (range 32-54). Their body weight averaged $86 \mathrm{~kg}$ (range $46-107 \mathrm{~kg}$ ) and none was obese, the relative body weights being less than $130 \%$ of their ideal. The fasting serum triglyceride concentration in this group ranged between $254-740 \mathrm{mg} / 100 \mathrm{ml}$. Analysis of the triglyceride content of the various lipoprotein fractions isolated by preparative ultracentrifugation [14] showed that $78-90 \%$ of the total serum triglyceride was present in the very low density lipoprotein $(\mathrm{d}<1.006)$, indicating that the hypertriglyceridaemia in these patients was of endogenous origin. No evidence of thyroid disease, renal disorder or excessive alcoholism was demonstrable. At the time of the study none were taking any drug known to affect lipid metabolism. Insulin resistance was demonstrable during an oral glucose tolerance test showing much higher insulin response than normal subjects. Further information concerning the clinical details of these patients, plasma lipoprotein analysis and glucose tolerance results have been presented in another publication [6].

Before the investigation all subjects were stabilised on an isocaloric diet. This diet provided 35 calories $/ \mathrm{kg} /$ day, of which $38 \%$ was carbohydrate, $45 \%$ fat and $17 \%$ protein. The diet was maintained for the three week period of the study during which time their weight remained steady. The nature of the test was explained to every patient before their entry into the study and informed consent was obtained.

\section{Methods}

\section{Preparation of $I^{131}$ VLDL}

$50-100 \mathrm{ml}$ of plasma was obtained from each patient to isolate the very low density lipoproteins $(\mathrm{d}<1.006)$ using preparative ultracentrifugation [14]. The lipoprotein fraction was then concentrated, washed by two successive ultracentrifugations and then iodinated with $\mathrm{I}^{131}$ using the methodology described previously [6]. In order to achieve selective labelling of the B-apoprotein of VLDL the labelled lipoproteins were reincubated with the patient's own HDL rich plasma to facilitate the exchange of labelled $\mathrm{C}$-apoprotein and some of the lipid in VLDL with similar components in HDL. Following incubation the VLDL fraction was re-isolated by recentrifugation, and the B-apoprotein in the separated VLDL was found to contain $82-98 \%$ of the total radioactivity.

\section{Preparation of $I^{125} \mathrm{LDL}$}

Low density lipoproteins (d 1.019-1.063) were isolated from the plasma infranatant remaining after sep- 


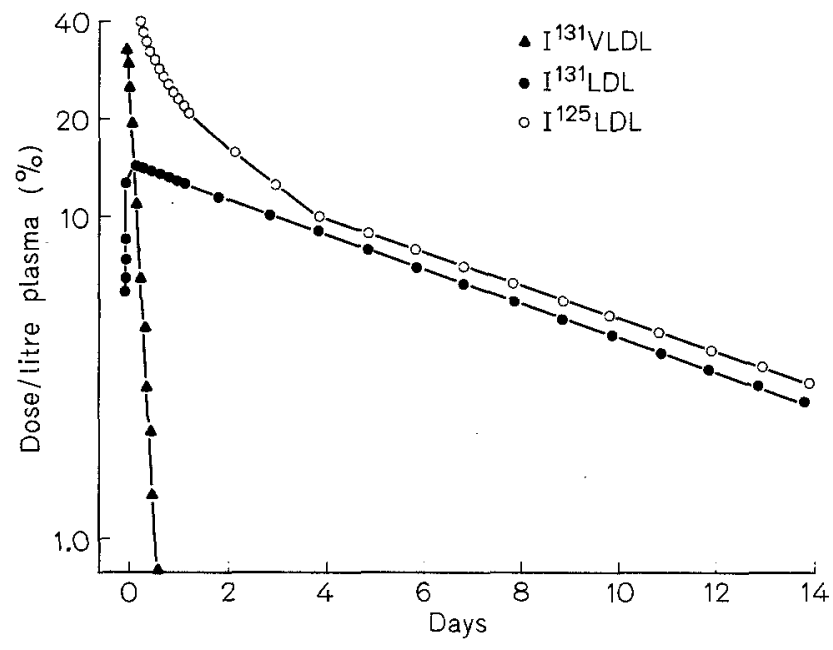

Fig. 1. Plasma VLDL B-apoprotein and LDL radioactivity curves following the simultaneous injection of $\mathrm{I}^{131} \mathrm{VLDL}$ and $\mathrm{I}^{125} \mathrm{LDL}$ to a normal subject

aration of VLDL using preparative ultracentrifugation. The LDL fraction thus isolated was rewashed and concentrated by repeated recentrifugation at the same density. Samples of this preparation gave single precipitation lines when tested by immunoelectrophoresis [15] or immunodiffusion [16]. The concentrated LDL was dialysed against several changes of $0.9 \%$ saline containing $0.01 \%$ EDTA and then iodinated using the McFarlane jet technique [17]. This procedure facilitated the introduction of about 0.5 atoms of iodine per molecule of LDL. The unbound $\mathrm{I}^{125}$ was removed by dialysis against $6-8$ changes of $0.9 \%$ saline. In the dialysed preparation $<3 \%$ of the total radioactivity was extractable in chloroform methanol $(2: 1, V / V)$, the remaining radioactivity being bound to the protein moiety.

\section{Injection of Radioactive Lipoproteins and Collection of Samples}

Patients were given Lugol's iodine, 5 drops/day one day before the start of the study and during the whole period of investigation, to block thyroid uptake of radioactive iodine. Patients were admitted to the metabolic ward. After an overnight fast a catheter was inserted into an antecubital vein for injection and another catheter was introduced into the superior vena cava for sampling. Each patient received 6-8 mg of his own plasma VLDL labelled in the B-apoprotein with $\mathrm{I}^{131}\left(25-40 \mu \mathrm{ci}\right.$.) and $10-15 \mathrm{mg}$ of $\mathrm{I}^{125} \mathrm{LDL}$ (40-60 $\mu \mathrm{ci}$ ). The total dose of each of the radioactive materials was checked by accurate weighing of syringe contents. Standards were prepared from aliquots to be used as a reference during the counting of samples.
Before injection into the patients the lipoproteins were passed through a Millipore filter $(0.45 \mu)$ and diluted in saline. The labelled lipoproteins were given as a pulse injection and samples of blood were obtained $10 \mathrm{~min}$ after the injection and at one hourly intervals for the first $12 \mathrm{~h}$. Thereafter samples were obtained every $2 \mathrm{~h}$ for a further period of $12 \mathrm{~h}$ and then daily for another 2 weeks. During the first $24 \mathrm{~h}$ following the injection of tracer urine was collected in 4 hourly aliquots. $24 \mathrm{~h}$ urine collections were then performed for a period of 2 weeks. The urine was collected into bottles containing sodium iodate and potassium iodide crystals.

The plasma VLDL and LDL fractions in each blood sample were isolated and washed by repeated centrifugation. Total radioactivity $\left(\mathrm{I}^{131}\right.$ and $\left.\mathrm{I}^{125}\right)$ was determined in each aliquot and corrected for physical decay. The VLDL B-apoprotein was separated from the C-apoprotein by the tetramethyl urea precipitation [18] and protein estimations were performed according to Lowry et al. [19]. Measurement of the protein concentration in plasma LDL was also performed on aliquots of this lipoprotein fraction.

The daily excretion of $I^{131}$ and $I^{125}$ was determined on aliquots of urine. Each urine sample was checked for proteins and results of patients with significant proteinuria were excluded from the study, as these patients could lose some of the labelled lipoproteins directly in urine [20].

\section{Interpretation of Data and Calculations}

The $\mathrm{I}^{131}$ and $\mathrm{I}^{125}$ radioactivity present in VLDL and LDL per litre of plasma was expressed as a percentage of the corresponding dose of radioactivity injected into each patient and plotted versus time on a semilogarithmic scale. Figure 1 shows a representative study in one of our subjects. During the first day after the injection the $\mathrm{I}^{131}$ radioactivity associated with plasma VLDL disappeared rapidly. Thereafter $<0.1 \%$ of the injected radioactive dose was detected in this lipoprotein fraction. The $\mathrm{I}^{131}$ radioactivity associated with LDL, on the other hand, increased progressively and peaked 12-18 $\mathrm{h}$ after the injection. Thereafter the radioactivity in this lipoprotein fraction disappeared gradually with a decay rate which was considerably slower than that seen in plasma VLDL. The $I^{131}$, VLDL and LDL curves intersected at the maximal height of the LDL curve, confirming a precursor product relationship between the B-apoprotein in plasma VLDL and LDL as suggested previously $[21,23]$.

The $\mathrm{I}^{125}$ curve showed an initial rapid decline merging with a single exponential phase by about the 4th day after the injection of radioactive material 

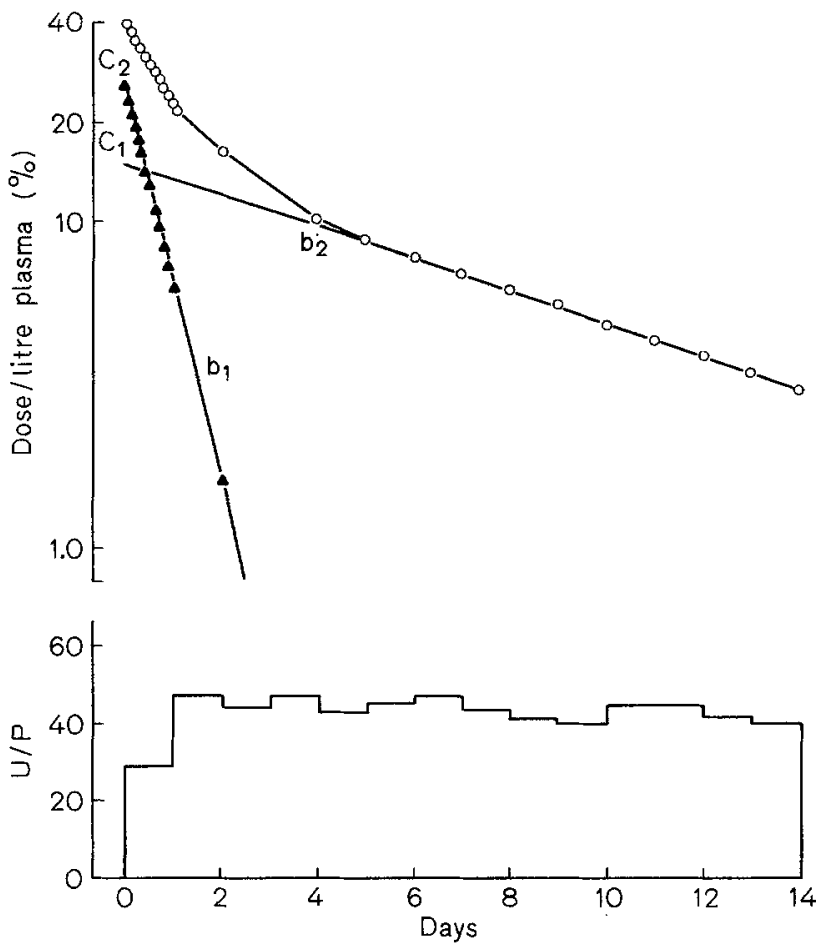

Fig. 2. Plasma LDL and urine radioactivities following the injection of $\mathrm{I}^{125} \mathrm{LDL}$ to a normal subject. For symbols $\mathrm{C} 1, \mathrm{C} 2$, b1 and b2 see text. $\mathrm{U} / \mathrm{P}=$

$\mathrm{I}^{125}$ radioactivity excreted in urine per 24 hours

$\mathrm{I}^{125}$ radioactivity in plasma $\mathrm{LDL}$ at 0.36 day of the urine collection period

(Fig. 2). This pattern is consistent with two exponential compartments assuming that, after day 4 , plasma LDL had equilibrated with an extravascular pool [24].

From the $\mathrm{I}^{131}$ and the $\mathrm{I}^{125}$ plasma curves and the excretion of the isotopes in urine the following kinetic parameters of VLDL and LDL metabolisms were estimated.

a. Total Plasma Flux of VLDL B-Apoprotein. The fractional turnover rate (FTR) of plasma VLDL $\mathrm{B}$-apoprotein was calculated from $\mathrm{t}^{1 / 2}$ of the disappearance curve of $I^{131}$ VLDL plotted on a semilogarithmic scale. The absolute turnover rate or the daily plasma flux of VLDL B-apoprotein was determined from the circulating mass of the apoprotein and its fractional turnover rate [6].

b. Conversion of $V L D L B$-Apoprotein to $L D L$. The conversion rate of VLDL B-apoprotein into LDL was calculated from the LDL $I^{131}$ and $I^{125}$ plasma radioactivity curves, each expressed as a percentage of the injected dose per litre of plasma, as shown in Figure 1. Since the LDL ${ }^{125}$ curve can be regarded as reflecting $100 \%$ conversion into $\mathrm{LDL}$, the ratio of $\mathrm{LDL}$
$\mathrm{I}^{131}:$ LDL $\mathrm{I}^{125}$ when the decay curves are parallel represents the fraction of labelled VLDL converted to LDL. To allow for the fact that the $\mathrm{I}^{125} \mathrm{LDL}$ injected intravenously has been in the circulation for a longer time than the $\mathrm{I}^{131}$, the ratio was calculated from the $I^{125}$ LDL curve at time $t$ and that of the $I^{131} \mathrm{LDL}$ at time $\mathrm{t}+\overline{\mathrm{t}} . \overline{\mathrm{t}}$ represents the mean conversion time calculated in each subject by integration of the radioactivity curves according to Hart and Spencer [22]. This formulation has been adopted previously for the study of VLDL B-apoprotein metabolism in man by Sigurdsson [23].

c. Degradation of VLDL B-Apoprotein. Theoretically the rate of excretion of $\mathrm{I}^{131}$ during the first $24 \mathrm{~h}$ following the injection of labelled material represents the sum of radioactivities resulting from catabolism of $\mathbf{I}^{131}$ LDL derived from VLDL interconversion and that resulting from the direct degradation of $I^{131}$ VLDL molecules. However, the relative contribution of the former during this initial period could be considered negligible, since the fractional turnover rate of VLDL is at least one order of magnitude faster than that of LDL. The urinary ${ }^{131}$ excretion during the first $24 \mathrm{~h}$ was therefore considered to represent the mass of labelled VLDL available for direct degradation via a pathway which does not involve its conversion to LDL. This, when expressed as a percentage of the injected dose of radioactivity, would give the fraction of circulating VLDL B-apoprotein which is metabolised by direct degradation. The absolute degradation rate could then be determined from this ratio and the total circulating mass of VLDL B-apoprotein.

d. LDL Catabolism. The $\mathrm{I}^{125} \mathrm{LDL}$ curve was resolved into two exponentials as shown in Figure 2 and was analysed according to the two compartment models of Matthews [24]. In this method it is assumed that the intravascular LDL pool had equilibrated with and was exchanging with an extravascular pool; and that the catabolism of protein was occurring at a site in continuity with the intravascular pool. It was further assumed that the metabolism of LDL during the experimental period was proceeding at a steady state and hence a constant rate of catabolism was balanced by a similar rate of synthesis, since the daily fluctuations in the fasting plasma levels of LDL did not exceed $10 \%$.

If $b 1$ is the slope of the exponential 1 , and b2 is the slope of exponential 2 and $\mathrm{C} 1, \mathrm{C} 2$ respresent the intercepts of these exponentials with the zero time respectively (see Fig. 2 for symbols) then; the fractional transfer rate from intravascular pool to the extravascular compartment $(\mathrm{K} 1,2)$ can be derived from the equation: 


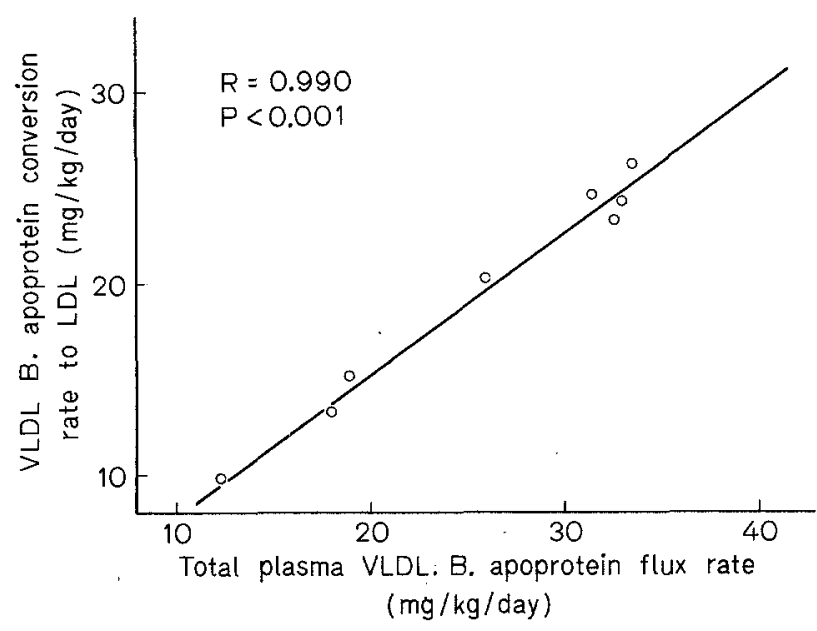

Fig. 3. Correlation between total plasma VLDL B-apoprotein flux and the conversion rate of this apoprotein to plasma $L D L$ in normal subjects

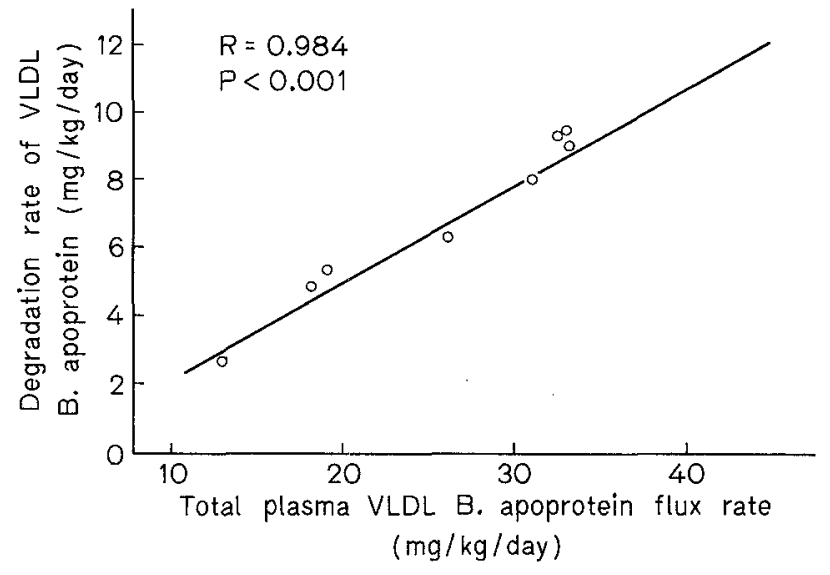

Fig. 4. Correlation between total plasma VLDL B-apoprotein flux and the degradation rate of this apoprotein in normal subjects

Table 1. Plasma VLDL B-apoprotein and LDL metabolism in normal subjects

\begin{tabular}{|c|c|c|c|c|c|c|c|c|}
\hline \multirow[t]{2}{*}{ Subject } & \multicolumn{4}{|c|}{ VLDL B-apoprotein } & \multicolumn{4}{|c|}{ LDL apoprotein } \\
\hline & $\begin{array}{l}\text { Circulating } \\
\text { mass } \\
(\mathrm{mg})\end{array}$ & $\begin{array}{l}\text { Total plasma } \\
\text { flux } \\
\text { (mg/kg/day) }\end{array}$ & $\begin{array}{l}\text { Conversion } \\
\text { to } \mathrm{LDL} \\
\text { (mg/kg/day) }\end{array}$ & $\begin{array}{l}\text { Degradation } \\
\text { (mg/kg/day) }\end{array}$ & $\begin{array}{l}\text { Circulating } \\
\text { mass } \\
(\mathrm{gm})\end{array}$ & $\begin{array}{l}\% \\
\text { Extravascular }\end{array}$ & $\operatorname{FCR}\left(D^{-1}\right)$ & $\begin{array}{l}\text { Catabolic } \\
\text { rate } \\
(\mathrm{mg} / \mathrm{kg} / \text { day })\end{array}$ \\
\hline 1. & 150 & 18.2 & 13 & 4.8 & 1.27 & 35 & 0.54 & 12.5 \\
\hline 2. & 360 & 32.6 & 23.6 & 9.2 & 3.53 & 45 & 0.56 & 24 \\
\hline 3. & 180 & 25.9 & 20 & 6.2 & 1.75 & 38 & 0.57 & 18.9 \\
\hline 4. & 160 & 19.2 & 14.9 & 5.4 & 1.65 & 42 & 0.60 & 15 \\
\hline 5. & 120 & 12.5 & 9.8 & 2.5 & 1.43 & 31 & 0.52 & 11 \\
\hline 6. & 580 & 33.6 & 26 & 9.1 & 3.73 & 46 & 0.63 & 26 \\
\hline 7. & 420 & 33.0 & 24 & 8.4 & 3.52 & 40 & 0.70 & 24.6 \\
\hline 8. & 290 & 31.7 & 25.5 & 8.0 & 2.75 & 42 & 0.61 & 26.4 \\
\hline $\begin{array}{l}\text { Mean } \pm S E M \\
\text { Range }\end{array}$ & $\begin{array}{l}282 \pm 57 \\
(120-580)\end{array}$ & $\begin{array}{l}25.9 \pm 2.9 \\
(12.5-33.6)\end{array}$ & $\begin{array}{l}20 \pm 2 \\
(9.8-26)\end{array}$ & $\begin{array}{l}6.8 \pm 0.9 \\
(2.5-9.2)\end{array}$ & $\begin{array}{l}2.45 \pm 0.37 \\
(1.27-3.73)\end{array}$ & $\begin{array}{l}40 \pm 1.8 \\
(31-46)\end{array}$ & $\begin{array}{l}0.59 \pm 0.015 \\
(0.52-0.70)\end{array}$ & $\begin{array}{l}19.8 \pm 2.2 \\
(11-26.4)\end{array}$ \\
\hline
\end{tabular}

Table 2. Plasma VLDL B-apoprotein and LDL metabolism in patients with insulin resistance and endogenous hypertriglyceridaemia

\begin{tabular}{|c|c|c|c|c|c|c|c|c|}
\hline \multirow[t]{2}{*}{ Subject } & \multicolumn{4}{|c|}{ VLDL B-apoprotein } & \multicolumn{4}{|c|}{ LDL apoprotein } \\
\hline & $\begin{array}{l}\text { Circulating } \\
\text { mass } \\
(\mathrm{mg})\end{array}$ & $\begin{array}{l}\text { Total plasma } \\
\text { flux } \\
\text { (mg/kg/day) }\end{array}$ & $\begin{array}{l}\text { Conversion } \\
\text { to LDL } \\
\text { (mg/kg/day) }\end{array}$ & $\begin{array}{l}\text { Degradation } \\
\text { (mg/kg/day) }\end{array}$ & $\begin{array}{l}\text { Circulating } \\
\text { mass } \\
(\mathrm{gm})\end{array}$ & $\begin{array}{l}\% \\
\text { Extravascular }\end{array}$ & $\mathrm{FCR}\left(\mathrm{D}^{-1}\right)$ & $\begin{array}{l}\text { Catabolic } \\
\text { rate } \\
(\mathrm{mg} / \mathrm{kg} / \text { day })\end{array}$ \\
\hline \multicolumn{9}{|c|}{ Non-diabetic idiopathic hypertriglyceridaemia: } \\
\hline 9. & 1390 & 49.5 & 32.5 & 5.2 & 3.64 & 38 & 0.89 & 30.2 \\
\hline 10. & 680 & 37.7 & 28.6 & 2.4 & 3.96 & 44 & 0.62 & 27.4 \\
\hline 11. & 760 & 50.4 & 34 & 6.8 & 3.08 & 42 & 0.78 & 32.2 \\
\hline 12. & 910 & 47.3 & 29.2 & 9.0 & 3.47 & 35 & 0.89 & 29.6 \\
\hline \multicolumn{9}{|c|}{ Maturity-onset diabetics with hypertriglyceridaemia: } \\
\hline 13. & 1960 & 56.5 & 34.6 & 8.4 & 3.61 & 36 & 0.75 & 31.5 \\
\hline 14. & 1990 & 46.8 & 29.4 & 8.2 & 2.28 & 44 & 0.89 & 30.4 \\
\hline 15. & 1890 & 39.6 & 30.5 & 6.0 & 3.18 & 40 & 0.69 & 29.5 \\
\hline \multicolumn{9}{|c|}{ Lipodystrophic diabetes with hypertriglyceridaemia: } \\
\hline 16. & 970 & 22 & 9.2 & 1.8 & 2.03 & 42 & 0.27 & 10.5 \\
\hline 17. & 1000 & 18.6 & 8.4 & 1.4 & 1.89 & 38 & 0.23 & 9.4 \\
\hline
\end{tabular}




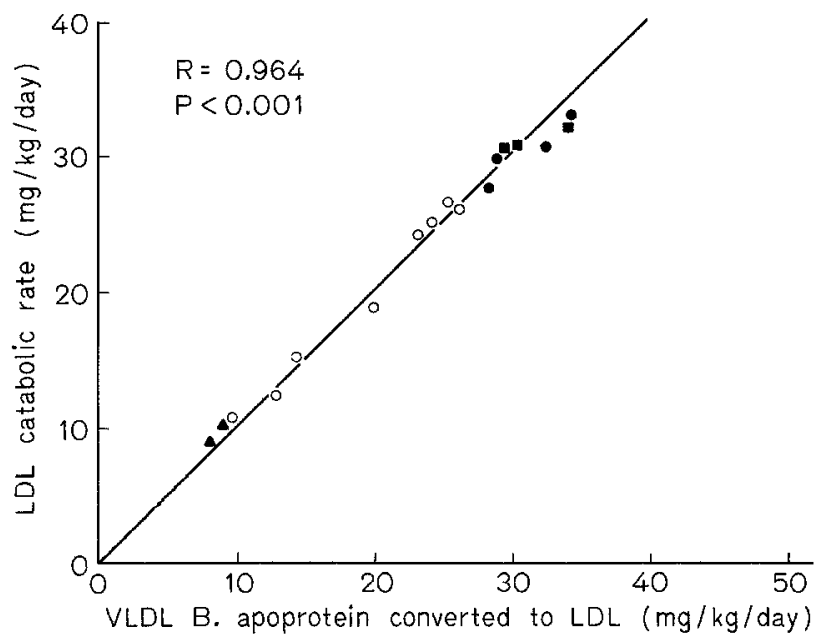

Fig. 5. Relation between the conversion rate of plasma VLDL B-apoprotein to LDL and the catabolic rate of the latter. The continuous line represents the identity between the two measurements

$0=$ normal subjects

$\bullet=$ adult onset diabetics

- = idiopathic hypertriglyceridaemia

^ = patients with lipodystrophy

$$
(\mathrm{K} 1,2)=\frac{\mathrm{C} 1 \mathrm{C} 2(\mathrm{~b} 2-\mathrm{b} 1)^{2}}{\mathrm{C} 1 \mathrm{~b} 2+\mathrm{C} 2 \mathrm{~b} 1}
$$

and the fractional transfer rate from extravascular to intravascular pool $(\mathrm{K} 2,1)$ from the equation:

$$
(\mathrm{K} 2,1)=\mathrm{C}_{1} \mathrm{~b} 2+\mathrm{C}_{2} \mathrm{~b} 1
$$

The ratio $\frac{(\mathrm{K} 1,2)}{(\mathrm{K} 2,1)}=\frac{\text { extravascular mass of LDL protein }}{\text { intravascular mass of LDL protein }}$

From this ratio the percentage of total LDL mass lying extravascularly and exchanging with the plasma can be calculated.

The fractional catabolic rate of plasma LDL was derived from the U/P ratio, which represents the total $\mathrm{I}^{125}$ excretion per $24 \mathrm{~h}$ divided by the total plasma isotope level at time 0.36 day of the corresponding urine collection period. In this method it is assumed that the catabolism of labelled protein was proceeding at a steady rate and that the amount of isotope appearing in urine was proportional to the mass of labelled protein available for catabolism over a given period of observation. It was further assumed that the breakdown of both the intravascular and extravascular labelled LDL occurs at a site in close proximity with the intravascular compartment, and that the isotope from broken down protein was rapidly and irreversibly eliminated from this compartment via the urine. The absolute rate of plasma LDL catabolism in $\mathrm{mg} / \mathrm{kg} /$ day was then calculated from the circulating mass of this lipoprotein and the fractional catabolic rate.

\section{Results}

\section{Conversion of VLDL B-Apoprotein to $L D L$}

Table 1 shows that in normal subjects the conversion of plasma VLDL B-apoprotein to plasma LDL corresponds to $72-83 \%$ of the total VLDL B-apoprotein. These results suggest that in normal subjects a major pathway for VLDL B-apoprotein catabolism involves its ultimate conversion to LDL molecules. Furthermore, a close correlation was demonstrable between the total daily apoprotein flux and the absolute rate of its conversion to LDL, indicating that the synthesis of the latter is proportionate to the daily flux of plasma VLDL B-apoprotein (Fig. 3).

In the patients with idiopathic hypertriglyceridaemia and in the adult onset diabetics (Table 2) the circulating mass of VLDL B-apoprotein was 2-6 fold higher than that of the normal subjects. This increase was associated with enhancement of the total VLDL B-apoprotein production. The absolute rate for conversion of VLDL B-apoprotein to LDL was also increased in these patients. This increase, however, was not proportionate to the enhanced daily flux of plasma VLDL B-apoprotein, resulting in a reduction in the fractional conversion to LDL.

The 2 patients with lipodystrophic diabetes had normal rates of plasma VLDL B-apoprotein flux, despite a three-fold increase in the circulating mass of this protein, suggesting that the elevation in plasma VLDL in these patients was due to impaired removal of this lipoprotein. As shown in Table 2 the absolute conversion rate of VLDL B-apoprotein to LDL was lower in these patients than in normal subjects, accounting for only $42-46 \%$ of the total daily flux of the former.

\section{Degradation of VLDL B-Apoprotein}

The $I^{131}$ excreted in the urine in the normal subjects represented a degradation rate which corresponded to $21-28 \%$ of the total daily flux of plasma VLDL $\mathrm{B}$-apoprotein. In these patients the degradation rate was proportionate to the total daily flux (Fig. 4). The degradation fraction, when summed with the values for conversion to LDL, aproximated to the total daily flux of plasma VLDL B-apoprotein, suggesting that in normal subjects these two pathways could well account for the total removal of this apoprotein.

The results shown in Table 2 indicate that the 
values for the degradation rate of VLDL B-apoprotein in patients with idiopathic hypertriglyceridaemia and in the adult onset diabetics fell within the normal range, despite a marked enhancement of the plasma flux of this apoprotein. Thus they represented only $6-18 \%$ of the total daily flux. The sum of the VLDL B-apoprotein metabolised by degradation and by conversion to $\mathrm{LDL}$ was less than the total daily removal of this protein, with $8-25 \%$ unaccounted for by either of these processes.

In the 2 patients with lipodystrophy the degradation rates of plasma VLDL B-apoprotein were lower than the normal range despite normal flux rates of plasma VLDL. Thus about $50 \%$ of the total VLDL B-apoprotein flux could not be explained by either its conversion to LDL or degradation.

\section{Plasma LDL Apoprotein Catabolism}

As shown in Tables 1 and 2, the circulating mass of LDL apoprotein and the percentage of total pool present extravascularly in the patients with idiopathic hypertriglyceridaemia, maturity onset diabetes and lipodystrophic subjects were within the normal range. In patients with idiopathic hypertriglyceridaemia and adult onset diabetes, however, the values for the absolute catabolic rates of plasma LDL calculated from the $U / P$ ratio were higher than normal. In contrast, the two patients with lipodystrophy had catabolic rates which were lower than normal.

In all the subjects studied the U/P ratio was nearly constant during the experimental period, suggesting that LDL was homogeneously labelled with $\mathrm{I}^{125}$ and that its metabolism had been proceeding at a steady rate; hence the rate of LDL catabolism could be equated to the synthetic rate. Figure 5 shows a close agreement between the catabolic rate values of plasma LDL apoprotein calculated from the U/P and the conversion rate of plasma LDL B-apoprotein to LDL. These results suggest that both in the normal subjects and all the patients investigated almost all of the LDL molecules are derived from the metabolic conversion of the VLDL B-apoprotein.

\section{Discussion}

Our data indicate that the fate of plasma VLDL in man involves the conversion of some of its constituents to plasma LDL. Thus, in normal subjects, the conversion of VLDL B-apoprotein to LDL accounted for $72-83 \%$ of the total daily flux and was proportionate to the turnover rate of this apoprotein. Examination of the urinary excretion of $\mathbf{I}^{131}$ indicated that $21-28 \%$ of the total daily flux of VLDL B-apoprotein was degraded and that this amount was also proportionate to the total VLDL B-apoprotein flux. These results suggest an alternative pathway for VLDL B-apoprotein catabolism which does not involve its prior conversion to LDL and which could be of importance in determining the fate of these molecules. Indeed, experiments in rats $[25,26]$ have shown that the major part of plasma VLDL B-apoprotein removed from the circulation is degraded, presumably in the liver, without conversion to LDL, which could explain the relatively low plasma LDL concentration observed in this animal.

In the patients with idiopathic hypertriglyceridaemia and adult onset diabetes the total daily flux rates of plasma VLDL B-apoprotein were increased, suggesting enhanced production of these molecules. Nevertheless, the fraction of the daily flux converted to LDL was markedly reduced. The reduced conversion of VLDL in these patients could be explained in two ways. On the one hand, the processes which catalyse this conversion might follow a saturable system; hence, despite an increase in VLDL B-apoprotein flux, the conversion rate will be limited, representing a normal physiological response. On the other hand, the reduction in the fractional conversion of VLDL B-apoprotein to LDL might be due to reduced sensitivity of adipose tissue to the actions of insulin. In a previous communication we have shown that these patients have enhanced lipolysis despite marked hyperinsulinaemia [6]. The insulin resistance in this tissue could therfore prevent the lipoprotein lipase from increasing to compensate for the accelerated VLDL flux, thus limiting its conversion to LDL. The latter possibility is the more likely in the two patients with diabetic lipodystrophy, in whom the insulin resistance was associated with normal VLDL B-apoprotein flux although the fraction converted to LDL was markedly reduced. In all the patients studied the fraction of VLDL B-apoprotein subjected to degradation was decreased, suggesting that the insulin resistance might also have imposed some restraint upon the degradation pathway, resulting in a decrease in the fraction of the apoprotein degraded per day.

An interesting observation in this study was that, in contrast to the situation in normal subjects, the sum of the VLDL B-apoprotein converted to LDL and that metabolised by degradation could not account completely for the total VLDL B-apoprotein removed from the plasma of the patients with insulin resistance. These results suggest that in these patients $8-25 \%$ of the total VLDL B-apoprotein removed from the plasma was retained in an extravascular compartment. The anatomical location of this compartment and its pathogenic importance in the development of atheroma remains uncertain. Studies with 
smooth muscle cultures [13], however, indicate that these structures could be active in the uptake of radioiodinated VLDL from the medium and that this uptake could be accelerated by an increase in the VLDL concentration. The radioactivity from these molecules seems to be retained intracellularly and is not released by trypsinization of the cells. It is therefore possible that the retained plasma VLDL fraction seen in our patients represents the enhanced uptake of these molecules, secondary to its accumulation in the plasma.

In the present study we have shown that in a steady state situation the estimated rate of VLDL $\mathrm{B}$-apoprotein conversion to LDL agreed closely with the catabolic rate for plasma LDL. These results indicate that in man the conversion of VLDL B-apoprotein to LDL serves as the main source of plasma LDL apoprotein. In patients with idiopathic hypertriglyceridaemia and in the adult onset diabetics the synthesis of LDL from this source was increased, but was compensated by an enhancement in the rate of its catabolism. In the two patients with lipodystrophy, on the other hand, both the synthesis and catabolism of LDL were equally decreased. Hence, in all our patients the size of plasma LDL pool and the percentage present extravascularly were similar to that of normal subjects.

It is not certain, however, whether the increase in LDL turnover seen in some of the patients could be of any pathogenic importance in the deposition of lipid rich material in arterial walls. Recent studies [13, 27] have indicated that peripheral tissues, including the smooth muscle cell of arterial structures, participate in the degradation of plasma LDL apoprotein and that during this process cholesterol could be retained in these cells. An increase in the turnover of plasma LDL apoprotein as seen in our patients could eventually lead to the accumulation of cholesterol in arterial structures. Such a mechanism could provide an additive pathway to explain the development of atheroma in many of the patients with endogenous hypertriglyceridaemia in whom the plasma LDL concentration is not usually elevated. Further studies are required to substantiate this hypothesis.

\section{References}

1. Nikkila, E. A., Ogala, K.: Role of hepatic L-alpha-glycerophosphate and triglyceride synthesis in production of fatty liver by ethanol. Proc. Soc. exp. Biol. (N.Y.) 113, 814-817 (1963)

2. Stout, R. W., Vallance Owen, J.: Insulin and atheroma. Lancet 1969 I, 1078-1080

3. Peters, N., Hales, C. N.: Plasma insulin concentration after myocardial infarction. Lancet 1965 I, 1144-1145

4. Welborn, T. A., Breckenridge, A., Rubenstein, A. H., Dollery,
C. T., Fraser, T. R.: Serum insulin in essential hypertension and in peripheral vascular disease. Lancet 1966 I, 1336-1337

5. Olefsky, J. M., Farquhar, J. W., Reaven, G. M.: Reappraisal of the role of insulin in hypertriglyceridaemia. Amer. J. Med. 57, 551-560 (1974)

6. Kissebah, A. H., Alfarsi, S., Adams, P. W., Wynn, V.: Role of insulin resistance in adipose tissue and liver in the pathogenesis of endogenous hypertriglyceridaemia in man. Diabetologia (in press)

7. Bierman, E. L., Stein, O., Stein, Y.: Lipoprotein uptake and metabolism by rat aortic smooth muscle cells in tissue culture. Circulat. Res. 35, 136-150 (1974)

8. Ross, R.: Growth of smooth muscle in culture and formation of elastic fibres. J. Cell Biol. 50, 172-186 (1971)

9. Ross, R., Glomset, J. A.: Atherosclerosis and arterial smooth muscle cell: Proliferation of smooth muscle is a key event in the genesis of the lesions of atherosclerosis. Science 180, 1332-1338 (1973)

10. Bilheimer, D. W., Eisenberg, S., Levy, R. I.: The metabolism of very low density lipoprotein proteins. I. Preliminary in vitro and in vivo observations. Biochim. biophys. Acta. (Amst.) 260, 212-221 (1972)

11. Eisenberg, S., Bilheimer, D. W., Levy, R. I.: The metabolism of very low density lipoprotein proteins. II. Studies on the transfer of apoproteins between plasma lipoproteins. Biochim. biophys. Acta. (Amst.) 280, 94-104 (1972)

12. Weinhouse, S., Hirsch, E. F.: Chemistry of atherosclerosis. I. Lipid and calcium content of the intima and of the media of the aorta with and without atherosclerosis. Arch. Path. 29, 31-40 (1940)

13. Bierman, E. L., Albers, J. J.: Lipoprotein uptake by cultured human arterial smooth muscle cells. Biochim. biophys. Acta. (Amst.) 388, 198-202 (1975)

14. Hatch, F. T., Lees, R. S.: Practical methods for plasma lipoprotein analysis. In: Advances in lipid research (eds. R. Paoletti, D. Kritchevsky), 6, p. 16. New York - London: Academic Press 1968

15. Levy, R. L., Lees, R. S., Frederickson, D. S.: The nature of pre-beta (very low density) lipoproteins. J. clin. Invest. 45, 63-77 (1966)

16. Brown, V. W., Levy, R. I., Frederickson, D. S.: Studies of protein in human plasma very low density lipoproteins. J. biol. Chem. 244, 5687-5693 (1969)

17. McFarlane, A. S.: Efficient trace-labelling of proteins with iodine. Nature 182, 53 (1958)

18. Kane. J. P.: A rapid electrophoretic technique for identification of sub-unit species of apoproteins in serum lipoproteins. Analyt. Biochem. 53, 350-356 (1973)

19. Lowry, O. H., Rosebrough, N. J., Farr, A. L., Randall, R. J.: Protein measurement with folinphenol reagent. J. biol. Chem. 193, 265-275 (1951)

20. Scott, P. J., White, B. M., Winterbourn, C. C., Hurley, P. J.: Low density lipoprotein peptide metabolism in nephrotic syndrome: A comparison with patterns observed in other syndromes characterised by hyperlipoproteinaemia. Aust. Ann. Med. 1, 1-15 (1970)

21. Zilversmit, D. B.: The design and analysis of isotope experiments. Amer. J. Med. 19, 832-848 (1960)

22. Hart, H., Spencer, $\mathrm{H}$.: Rate of initial entry of $\mathrm{Ca}^{47}$ and $\mathrm{Sr}^{85}$ from the intestine into the vascular space. Proc. Soc. exp. Biol. (N.Y.) 126, 365-371 (1967)

23. Sigurdsson, G., Nicoll, A., Lewis, B.: Interconversion of lipoproteins: Is all low density lipoprotein-peptide derived from very low density lipoprotein peptide. Clin. Sci. Mol. Med. 48, 149 (1975)

24. Matthews, C. M. E.: The theory of tracer experiments with $I^{131}$ labelled plasma proteins. Phys. in Med. Biol. 2, 36-45 (1957) 
25. Eisenberg, S., Rachmilewitz, D.: Metabolism of rat plasma very low density lipoprotein. I. Fate in circulation of the whole lipoprotein. Biochim. biophys. Acta. (Amst.) 326, 378-390 (1973).

26. Eisenberg, S., Rachmilewitz, D.: Metabolism of rat plasma very low density lipoprotein. II. Fate in circulation of apoprotein sub-units. Biochim. biophys. Acta. (Amst.) 326, 391-405 (1973)

27. Steinberg, D. S.: Degradation of LDL by peripheral tissues in vivo and in vitro. In: Familial Hypercholesterolaemia Workshop held at the Hammersmith Hospital, London. Sept. 8-10, 1975, p. 84-93
Received: March 19, 1976, and in revised form: June 26, 1976

Dr. A. H. Kissebah

The Alexander Simpson Lab.

for Metabolic Research

St. Mary's Hospital Medical School

Praed Street

London W2

England 